\section{Infection of Wheat Roots by Ascospores of Ophiobolus graminis}

Is 1933, Samuel and Garrett ${ }^{1}$ published their observation that ascospores are violently ejected from the perithecia of the fungus Ophiobolus graminis (Sace.) Sace. and thus become air-borne; it had previously been supposed that these spores were merely washed down into the soil by rain. Samuel and Garrett, therefore, suggested that the association between outbreaks of the take-all disease of wheat in its whiteheads form and seasons of good spring rainfall in South Australia might be connected with the occurrence of suitable conditions for liberation and dispersal of ascospores, and for subsequent infection of wheat roots by them. Later, however, Garrett ${ }^{2}$ reported that he had been unable to secure infection of wheat seedling roots by inoculation with ascospores when the seedlings were growing in unsterilized soil or sand. Infection was readily obtained, however, by inoculation of seedlings growing in completely sterile soil or sand. Garrett explained his results by postulating that the food reserves of an individual ascospore were insufficient for establishment of a progressive root infection, unless supplemented by the microbial nutrients liberated by soil sterilization, or by those provided by root excretions, which would be wholly available to the germinating ascospores in sterile, but not in unsterile, sand.

Garrett, therefore, concluded that infection by ascospores of $O$. graminis was unlikely to play any significant part in the epidemiology of the take-all disease. $\mathrm{He}$ pointed out that this disease can be satisfactorily controlled by starving the fungus out of the soil through the practice of crop rotation; this result would not be expected if crops grown on clean land could be regularly and widely infected by air-borne ascospores. In 1946, however, Garrett ${ }^{3}$ was shown outbreaks of take-all in wheat crops grown on the recently drained soils of the NoordOost polder of the former Zuider Zee in the Netherlands. As described by Bosma 4 , the freshly drained soil of a new polder is at first colonized by a sward of grass (and especially by species of Agrostis, which are known to be susceptible to infection by $O$. graminis). After ploughing up the grass sward, several crops of wheat are taken in succession; the first may show some patches of the takeall disease, and the second and third crops are often quite severely affected. It is virtually certain that the soil of any new polder, when first drained, is free from the presence of $O$. graminis, so that these observations by Bosma on the Noord-Oost polder once more raised the question as to whether the take-all disease could be spread to clean land by air-borne ascospores.

Although the negative results reported by Garrett in his ascospore inoculation trials seem convincing, several queries can be raised in the light of subsequent work. The dose applied by Garrett was generally $3 \times 10^{4}$ ascospores, applied in $1 \mathrm{ml}$. suspension; this suspension was either poured on to the surface of the soil around an established seedling, or added to the planting hole before sowing. Although this may seem a large dose, it is now known ${ }^{5}$ that some fungal spores have individually a very low probability of infection, so that a massive $E D_{50}$ is required. Secondly, it is known that soil exercises a strong filtering effect on spore suspensions, and it is also possible that placement of spores and timing of spore germination in relation to root emergence and growth may be critical for the occurrence of ascospore infection. With these considerations in mind, it was deemed worth while to make some fresh attempts at obtaining ascospore infection, directing particular attention to placement of spores and timing of spore germination in relation to root emergence.

Perithecia of $O$. graminis for these experiments were obtained both from naturally infected cereal stubble and from the roots of wheat seedlings grown over maizemealsand inoculum of the fungus in glass jars exposed to diffuse light. Wheat seedlings (var. 'Cappelle Desprez') were planted on the surface of moist, unsterilized soil or quartz sand in covered glass containers. After 6 days, the first three seminal roots of each seedling had emerged and were beginning to penetrate the soil; at this time the exposed surface of the proximal part of each root was inoculated with one drop $(0.024 \mathrm{ml}$.) of a suspension containing approximately $16 \times 10^{4}$ ascospores $/ \mathrm{ml}$. After a further period of 7 days, the exposed and inoculated parts of the seedling root systems were covered with unsterilized soil or sand similar to that on which the seeds had been sown. After 3 weeks from the time of inoculation, all seedlings were washed out for examination of the root system. Most of the inoculated roots showed infection characteristic of the take-all disease; the vascular cylinder was discoloured, and the surface of the root carried dark-coloured runner hyphæ of $O$. graminis. From these inoculated roots, $O$. graminis was isolated in pure culture.

These experiments have shown that, at least under optimal conditions, ascospores of $O$. graminis can infect the roots of wheat seedlings. This finding, taken in conjunction with the observations of Gregory and Stedman ${ }^{6}$ on the occurrence of these ascospores in the air spora, suggests the most probable explanation for the appearance of the take-all disease in wheat crops grown on the newly drained polders of the former Zuider Zee.

I thank Dr. S. D. Garrett for suggesting this problem to me. The work was carried out during my tenure of a postgraduate studentship given by the Agricultural Research Council.

Botany School,

D. H. Brooks

University of Cambridge.

${ }^{1}$ Samuel, G., and Garrett, S. D., Phytopath., 23, 721 (1933).

${ }^{2}$ Garrett, S. D., Ann. App. Biol., 26, 47 (1939).

s Garrett, S. D., Chron. Bot., 12, 181 (1948).

"Bosma, W. A., Versl. Dir. Wieringermeer (Noordoostpolderwerken), No. 3 (1946).

${ }^{5}$ Garrett, S. D., Plant Pathology, 3 (Academic Press, New Xork, 1960).

- Gregory, P. H., and Stedman, O. J., Trans. Brit. Mycol. Soc., 41, 449 (1958).

\section{Gynodicey in New Zealand Gentiana}

IN March 1964 the junior author noticed that populations of Gentiana bellidifolia Hook. f., a perennial alpine species, were heterœcious in several places in South Island, New Zealand, mountrains. Closer investigation revealed that the populations were gynodiceious. We sampled a population in Rough Creek basin, Arthurs Pass, at 5,000 ft. by taking one flower from each plant along a transect of some $500 \mathrm{ft}$. and found the following numbers and proportions of the sexes.

\begin{tabular}{|c|c|c|}
\hline & Hermaphrodite & Female \\
\hline $\begin{array}{l}\text { Number } \\
\text { Proportion }\end{array}$ & $\begin{array}{r}82 \\
3\end{array}$ & $\underset{1}{27}$ \\
\hline
\end{tabular}

Some 'intersexes'-flowers with one stamen and four staminodes-were also present. There is no doubt of the functional gynodicey of these populations. The proportions of hermaphrodite flowers setting seed were not established because the collection was made too early in the season; but some individuals, both females and hermaphrodites, bore ripening fruit full of seed. Indications are that most hermaphrodites set seed, although a few hermaphrodite flowers with withered gynocia were seen. No conclusions can yet be made about the mechanism for maintenance of the proportions of the sexes found in the sampled population (see ref. 1 for a brief discussion of the significance of the gynodiceious breeding system).

The differential expression of sex in flowers of gynodiocious species is often accompanied by size differences and other heteromorphic differences in floral parts. This pattern is followed by Gentiana bellidifolia although there is overlap in flower size between plants of different sex. Fig. 1 illustrates typical flowers of both types and Fig. 2 